\title{
Addendum to: Molecular characterization of a novel amalgavirus from the entomopathogenic fungus Beauveria bassiana
}

\author{
Igor Koloniuk $^{1}$ - Lenka Hrabáková, ${ }^{1,2}$ - Karel Petrzik ${ }^{1}$
}

(C) Springer-Verlag Wien 2015

\section{Addendum to: Arch Virol (2015) 160:1585-1588 \\ DOI 10.1007/s00705-015-2416-0}

In the above article [1], authors would like to add following statement to the acknowledgements:

"The authors would like to thank Noemi Herrero Asensio, Institute of Entomology, BC CAS, for her contribution to the initial screening of fungal cultures."

\section{Reference}

1. Koloniuk I, Hrabáková L, Petrzik K (2015) Molecular characterization of a novel amalgavirus from the entomopathogenic fungus Beauveria bassiana. Arch Virol 160:1585-1588

The online version of the original article can be found under doi:10.1007/s00705-015-2416-0.

Igor Koloniuk

koloniuk@umbr.cas.cz

1 Department of Plant Virology, Institute of Plant Molecular Biology, Biology Centre of the Czech Academy of Sciences, v.v.i., Branišovská 31, 37005 České Budějovice, Czech Republic

2 Department of Genetics, Faculty of Science, University of South Bohemia in České Budějovice, Branišovská 31a, 37005 České Budějovice, Czech Republic 